\title{
ANALISIS PERCEPATAN GETARAN TANAH MAKSIMUM WILAYAH YOGYAKARTA DENGAN METODE ATENUASI PATWARDHAN
}

Oleh:

\author{
Adam Haris ${ }^{1}, \operatorname{Irjan}^{2}$
}

\begin{abstract}
ABSTRAK: Gempabumi merupakan peristiwa alam yang sangat merusak dalam hitunggan waktu yang sangat singkat. Sebagai contoh gempabumi Yogyakarta yang terjadi pada tanggal 27 Mei 2006 dengan kekuatan 6,4 SR. Gempa tersebut banyak sekali memakan harta dan korban jiwa. Penelitian ini bertujuan untuk menganalisa dan mengetahui sebaran nilai percepatan getaran tanah daerah Yogyakarta dan untuk mengetahui tingkat risiko kerusakan yang diakibatkan gempa di daerah tersebut periode 1980-2010. Data yang digunakan dalam penelitian ini bersumbert dari USGS dengan skala magnitudo $\geq 4 \mathrm{SR}$, pada batasan $110^{\circ} 04 \mathrm{BT}-110^{\circ} 08 \mathrm{BT}$ dan $7^{\circ} 5 \mathrm{LS}-8^{\circ} 2 \mathrm{LS}$.

Metode yang digunakan dalam penelitian ini adalah metode atenuasi Patwardhan. Metode ini dipilih karena lebih sesuai dengan hasil verifikasi riil di lapangan sebagaimana telah dilaporkan oleh Sucipto, 2010 bahwa gempa merusak yang terjadi di Yogyakarta tercatat rata-rata memiliki intensitas antara V-VII MMI. Metode ini digunakan untuk menganalisis nilai percepatan getaran tanah dan nilai intensitas gempabumi sebagai acuan untuk mengetahui daerah yang rawan mengalami kerusakan akibat gempa.

Berdasarkan hasil penelusuran data USGS diketahui bahwa sebagian besar wilayah Yogyakarta didominasi gempa berskala 5 SR dengan tingkat seismisitas yang tinggi, dimana gempa-gempa berskala menengah ke atas sering terjadi di wilayah ini. Selanjutnya, setelah dilakukan analisa data dengan menghitung nilai percepatan getaran tanah diketahui bahwa nilai percepatan getaran tanah maksimum di daerah ini berkisar antara 50-60 gal. Sebaran daerah yang rawan mengalami kerusakan akibat gempa berkonsentrasi di kabupaten Bantul serta beberapa daerah Kulon Progo dan Gunung Kidul.
\end{abstract}

Kata Kunci : Gempabumi, Peak Ground Acceleration (PGA), intensitas, daerah rawan kerusakan.

\section{PENDAHULUAN}

Indonesia terletak di persimpangan tiga lempeng tektonik dunia, yaitu lempeng Australia, lempeng Asia (Eurasia) dan lempeng Pasifik. Ketiga lempeng ini bergerak relative antara satu terhadap yang lain. Pergerakan relatif ketiga lempeng ini merupakan penyebab utama aktivitas gempabumi di Indonesia. Indonesia juga tempat tumbuhnya gejala geologi tektonik baru antara gerak kerak bumi masa kuarter dengan zona seismic, sehingga wajar apabila Indonesia merupakan daerah rawan gempa. Bencana alam gempabumi merupakan fenomena alam yang tidak dapat diprediksi kejadiannya, namun bahaya resiko yang diakibatkan oleh gempabumi dapat dihindari dan dikurangi atau dimitigasi [4].

\footnotetext{
${ }^{1}$ Mahasiswa Jurusan Fisika Fakultas Sains dan Teknologi UIN Maliki Malang

${ }^{2}$ Staf pengajar pada Jurusan Fisika Fakultas Sains dan Teknologi UIN Maliki Malang
} 
Gempabumi merupakan peristiwa alam yang sangat dahsyat. Kerusakan yang ditimbulkannya tidak hanya menghancurkan harta benda, tetapi sering juga merenggut ribuan jiwa manusia, misalnya gempabumi Yogyakarta yang terjadi pada 27 Mei 2006 dengan kekuatan 6,4 SR. Akibat adanya gempa tersebut banyak sekali memakan korban harta dan jiwa. Menurut perkiraan gempa ini telah merusak 500.000 rumah penduduk, 6.000 korban jiwa, belum lagi kerusakan infrastruktur lain seperti infrastruktur jalan, jaringan listrik, air dan lain-lain [1].

Teori tektonik lempeng membagi bagian luar bumi menjadi dua lapisan. Lapisan paling luar, dinamakan litosfer bersuhu dingin dan kaku atau tegar. Di bawah litosfer terdapat lapisan astenosfer bersuhu panas. Litosfert mengalami perubahan bentuk secara perlahan-lahan dan terpecah-pecah menjadi sejumlah potongan lempeng yang mengapung di atas mantel astenosfer.

Pada dasarnya pergerakan lempeng kerak bumi dapat dibedakan atas pergerakan yang saling mendekati, saling menjauh, dan berpapasan. Pergerakan lempeng saling mendekati akan menyebabkan tumbukan dimana salah satu dari lempeng akan menujam ke bawah yang lain. Daerah penujaman membentuk suatu palung yang dalam, yang biasanya merupakan jalur patahan yang kuat. Di belakang jalur penujaman akan terbentuk rangkaian kegiatan magmatic dan gunung api serta berbagai cekungan pengendapan.

Gempabumi merupakan peristiwa alam yang secara fisik merupakan gerakan atau getaran kulit bumi yang disebabkan oleh gaya endogen atau kekuatan dari dalam bumi, misalnya gempabumi tektonik [2]. Gempa bumi tektonik (gempa bumi dislokasi) terjadi karena pergeseran letak lapisan kulit bumi. Gempabumi ini yang sangat hebat dan sering menimbulkan kerusakan besar. Kebanyakan pusat gempa tektonik terdapat di dasar laut [3].

Akibat usikan pada sumber gempa, gelombang merambat melalui medium yang dapat dilaluinya. Sumber getar gelombang yang terjadi akan menimbulkan tekanan sehingga mengakibatkan terjadinya tegangan, kemudian menggerakkan partikel-partikel di sekitarnya. Selama terjadi gempabumi, energi yang dilepaskan sumber gempabumi dirambatkan ke segala arah dalam bentuk gelombang seismik.

Gelombang gempabumi dapat diklasifikasikan menjadi dua kelompok, yakni gelombang badan (body waves) dan gelombang permukaan (surface waves).Gelombang Badan merupakan gelombang yang menjalar melalui bagian dalam bumi dan biasa disebut free wave karena dapat menjalar ke segala arah di dalam bumi. Gelombang ini dapat dibedakan lagi atas dasar cara merambatnya menjadi gelombang longitudinal atau 
gelombang primer (disingkat gelombang P) dan gelombang transversal atau gelombang sekunder (disingkat gelombang S). Gelombang permukaan, merupakan gelombang elastik yang menjalar sepanjang permukaan bumi yang disebut ride waves. Gelombang ini harus menjalar melalui suatu lapisan atau permukaan. Gelombang tersebut menyebabkan kerusakan pada bangunan atau tidak merusak sama sekali.
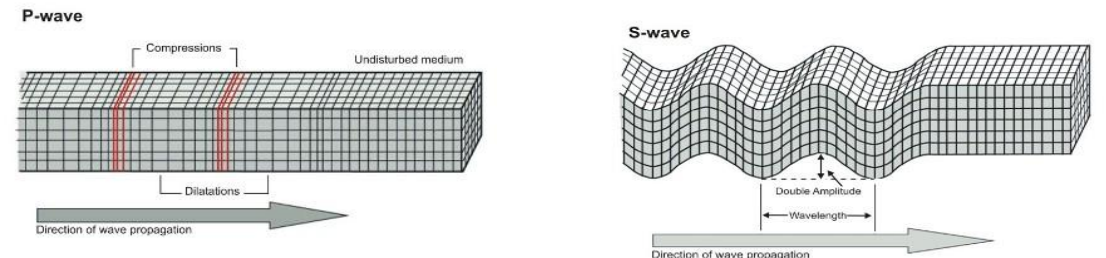

Gambar 1. Gelombang P dan S

Teori elastisitas pegas (Elastic Rebound Theory) merupakan teori yang menjelaskan bagaimana gempabumi terjadi Reid [5]. Menurut teori ini gempabumi terjadi pada daerah atau area yang mengalami deformasi. Energi yang tersimpan dalam deformasi akan terakumulasi sampai daya dukung batuan mencapai batas maksimum, hingga akhirnya menimbulkan rekahan atau patahan.

Penelitian ini bertujuan untuk menganalisa dan mengetahui sebaran nilai percepatan getaran tanah daerah Yogyakarta dan untuk mengetahui tingkat risiko kerusakan yang diakibatkan gempa di daerah tersebut. Data yang digunakan dalam penelitian ini bersumbert dari USGS periode 1980-2010 dengan skala magnitudo $\geq 4$ SR, pada batasan $110^{\circ} 04 \mathrm{BT}-110^{\circ} 08 \mathrm{BT}$ dan $7^{\circ} 5-8^{\circ} 2 \mathrm{LS}$. Selama rentang waktu tersebut diharapkan data yang diperoleh semakin valid serta mencakup data-data gempa skala menengah ke atas yang pernah melanda wilayah Yogyakarta.

Pengambilan data seismisitas dengan magnitude tersebut mengacu pada tingkat kekuatan gempabumi. Secara garis besar intensitas atau tingkat kerusakan yang terjadi akibat gempa bergantung dari kekuatan atau kualitas bangunan, kondisi geologi dan geotektonik lokasi bangunan serta percepatan tanah daerah lokasi gempabumi terjadi. Dari beberapa faktor tersebut percepatan tanah akibat gempa merupakan parameter yang perlu dikaji untuk setiap kejadian gempabumi.

Data gempa yang dipakai dalam penelitian ini berasal dari USGS dengan parameter yang diambil; lintang, bujur, kedalaman dan magnitude gempa. Langkah-langkah pemrosesan data ditempuh sebagai berikut:

1. Pengumpulan data dari USGS berupa Latitude, Longitude, Magnitude (Ms), Kedalaman, Waktu Kejadian. 
2. Perhitungan nilai Magnitude Surface (Ms).

3. Perhitungan percepatan getaran tanah dengan metode Patwardhan.

4. Menentukan percepatan getaran tanah maksimum (PGA)

5. Pengkonturan

6. Analisis Hasil

Percepatan getaran tanah permukaan di suatu tempat yang disebabkan oleh getaran seismik bergantung pada perambatan gelombang seismik dan karakteristik lapisan tanah (alluvial deposit) di tempat tersebut. Percepatan getaran tanah pemukaan pada penelitian ini di hitung berdasarkan model empiris yang diusulkan Patwardhan yaitu: $\ln a=\ln (363)$ $+0.587 \mathrm{Ms}-1.05 \ln \left(\mathrm{D}+0.864 \mathrm{e}^{0.463 \mathrm{Ms}}\right)$ dimana; $\mathrm{a}=$ percepatan tanah permukaan $(\mathrm{gal}), \mathrm{Ms}$ = Magnitudo gelombang permukaan, $\mathrm{D}=$ Jarak hiposenter $(\mathrm{km})$.

\section{HASIL DAN PEMBAHASAN}

Hasil perhitungan percepatan tanah maksimum dengan menggunakan model empiris yang diusulkan oleh Patwardhan dan pengkonturannya selanjutnya ditumpang-tindihkan dengan peta wilayah Yogyakarta. Hasil selengkapnya ditampilkan pada gambar berikut:

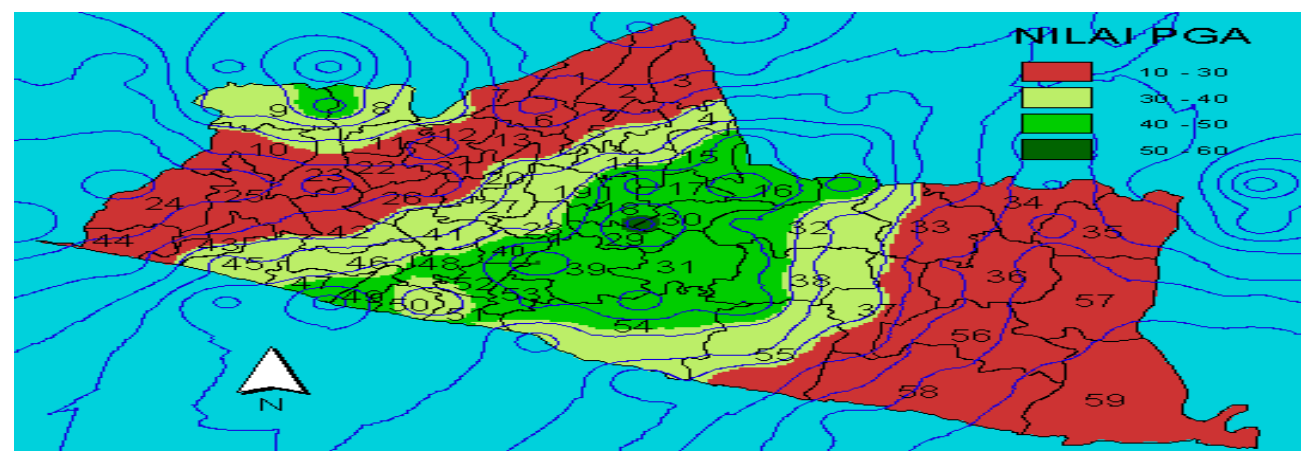

Gambar 2. Peta kontur percepatan getaran tanah maksimum model empiris Patwardhan

Dari gambar di atas dapat dijelaskan bahwa wilayah yang memiliki percepatan getaran tanah maksimum tertinggi yaitu antara 50 gal-60 gal (ditunjukkan oleh warna hijau tua) terkonsentrasi kecil di daerah Yogyakarta bagian tengah dengan nilai intensitas yang cukup tinggi yaitu V-VII MMI. Wilayah dengan nilai percepatan getaran tanah 40 gal - 50 gal (ditunjukkan oleh warna hijau muda) meliputi sebagian besar Yogyakarta bagian tengah dengan nilai intensitas IV-V MMI. Sedangkan untuk wilayah dengan nilai percepatan getaran tanah yang relative kecil yaitu sebesar 10 gal - 40 gal (ditunjukkan 
oleh warna merah dan hijau muda) meliputi daerah Yogyakarta bagian barat dan timur dengan nilai intensitas sebesar III-IV MMI.

Tabel 1. Klasifikasi percepatan getaran tanah maksimum (PGA) wilayah Yogyakarta berdasarkan model empiris Patwardhan

\begin{tabular}{|c|l|c|c|}
\hline No & \multicolumn{1}{|c|}{ Wilayah/Kecamatan } & $\begin{array}{c}\text { PG } \\
\text { (gal) }\end{array}$ & $\begin{array}{c}\text { Intensitas } \\
\text { (MMI) }\end{array}$ \\
\hline 1 & $\begin{array}{l}\text { Pakem, Cangkringan, Turi, Ngemplak, } \\
\text { Ngaglik, Sleman, Tempel, Mlati, Seyegan, } \\
\text { DIY, Godean, Minggir, Kalibawang, } \\
\text { Samigaluh, Girimulyo, Wates, Nanggulan, } \\
\text { Moyudan, Sedayu, Kokap, Pengasih, Panjatan, } \\
\text { Temon, Lendah, Tepus, Sentolo,Pajangan, } \\
\text { Kasihan, Sewon, Depok, Nglipar, Patuk, } \\
\text { Playen, Wonosari, Paliyan, Panggang, } \\
\text { Rongkop, Ponjong, Semanu, Karangmojo, } \\
\text { Semin, Ngawen, Kretek dan Sanden. }\end{array}$ & III-IV \\
\hline 3 & $\begin{array}{l}\text { Kalibawang, Patuk, Samigaluh, Kalasan, } \\
\text { Prambanan, Berbah, Banguntapan, DIY, } \\
\text { Piyungan, Dlingo, Playen, Panggang, Jetis, } \\
\text { Pundong, Bambanglipuro, Galur, Pandak, } \\
\text { Srandakan, Depok dan Pleret. }\end{array}$ & IV-V \\
\hline Banguntapan, Pleret dan Piyungan. & IV-VII \\
\hline
\end{tabular}

Secara umum, hasil pemetaan dari metode yang digunakan dalam penelitian ini menunjukkan bahwa wilayah yang memiliki tingkat rawan kerusakan paling tinggi yaitu di daerah kabupaten Bantul serta sedikit wilayah Kulon Progo dan Gunung Kidul sebagaimana yang telah di klasifikasikan pada tabel diatas.

Dengan struktur tanah yang didominasi dengan batuan breksi endapan gunung merapi wajar apabila daerah tersebut mengalami dampak kerusakan yang parah akibat gempa. Tanah dengan komposisi batuan yang mengendap dan mengeras padat maka struktur tanah tersebut akan sangat mudah dilalui oleh energi gelombang gempa yang melanda wilayah tersebut. Kejadian berbeda akan terjadi apabila suatu gelombang menjalar pada medium dengan komposisi batuan lunak atau medium yang tidak 
kompak, gelombang tersebut akan mengalami atenuasi dikarenakan dalam proses penjalarannya terhambat oleh sifat medium penghantarnya.

Selain itu, keberadaan sesar yang terletak di daerah Bantul juga sangat mempengaruhi tingkat kerusakan yang diakibatkan gempabumi, karena getaran gelombang yang dihasilkan akan bertambah besar apabila energi gelombang gempa yang berasal dari subduksi mengenai bidang sesar itu sendiri.

Penyebaran episenter gempa berdasarkan magnitudonya menunjukkan bahwa gempabumi dengan magnitude 4-6 SR sebagian besar tersebar di selatan provinsi Yogyakarta. Dapat diasumsikan bahwa tingginya aktivitas gempabumi di daerah ini dipicu oleh adanya zona subduksi sistem tektonik yang melintang memanjang di bagian selatan dari propinsi Yogyakarta. Oleh karena itu, wilayah Yogyakarta bagian selatan memiliki tingkat resiko yang tinggi terhadap kerusakan akibat gempabumi karena berada pada jarak yang lebih dekat dengan sumber gempa.

Untuk pembagian hiposenter gempa berdasarkan kedalamannya dapat dilihat bahwa gempa-gempa dangkal 0-30 km tersebar di selatan Yogyakarta. Kedalaman gempa juga merupakan faktor besar kecilnya dampak kerusakan yang dihasilkan oleh gempabumi. Dampak kerusakan yang dihasilkan oleh gempabumi dengan kedalaman dangkal memiliki resiko kerusakan yang lebih tinggi dibandingkan dengan kedalaman yang cukup dalam. Hal ini disebabkan karena semakin dangkal jarak hiposenter gempa maka semakin tinggi nilai percepatan tanah yang dihasilkan, dan sebaliknya semakin dalam hiposenter gempa maka semakin kecil nilai percepatan tanah yang dihasilkan.

Selan itu, gelombang yang melalui lapisan sedimen juga akan menimbulkan resonansi. Ini disebabkan karena gelombang gempa mempunyai spektrum yang lebar sehingga hanya gelombang gempa yang sama dengan periode dominan tanah dari lapisan sedimen yang akan diperkuat. Bangunan yang berada di atasnya akan menerima getarangetaran tersebut, dimana arahnya dapat diuraikan menjadi dua komponen yaitu komponen vertikal dan komponen horizontal. Untuk getaran yang vertikal, pada umumnya kurang membahayakan sebab searah dengan gaya gravitasi. Sedangkan untuk komponen horizontal menyebabkan keadaan bangunan seperti diayun. Bila bangunan itu tinggi, maka dapat diumpamakan seperti bandul yang mengalami getaran paksa (force vibration) sehingga membahayakan.

Proses kerja gaya yang mengenai bangunan [6] sebagai berikut : (1) Gempa bumi akan melepaskan energi gelombang yang dapat menjalar di permukaan tanah. Bila gelombang ini sampai pada pondasi bangunan dan menggerakkan bangunan, sehingga 
pondasi yang mulanya diam akan melakukan tanggapan dan getaran yang berupa reaksi inersia yang arahnya berlawanan dengan kinerja getaran yang diterima pondasi. (2) Getaran yang diteruskan ke bagian atas akan diteruskan kembali ke bagian bawah. Namun gaya horizontal itu tidak bekerja murni pada bangunan karena diimbangi oleh gaya berat bangunan.

\section{KESIMPULAN}

1. Hasil analisis percepatan getaran tanah maksimum menggunakan model empiris yang diusulkan oleh Patwardhan untuk wilayah Yogyakarta dan sekitarnya periode gempa 1980-2010 menunjukkan bahwa daerah yang memiliki percepatan getaran tanah maksimum tertinggi pertama yaitu antara 50 gal-60 gal terkonsentrasi kecil di daerah Yogyakarta bagian tengah dengan nilai intensitas yang cukup tinggi yaitu V-VII MMI. Daerah dengan nilai percepatan getaran tanah maksimum tertinggi kedua 40 gal - 50 gal meliputi sebagian besar Yogyakarta bagian tengah dengan nilai intensitas IVV MMI. Sedangkan untuk daerah dengan nilai percepatan getaran tanah maksimum tertinggi ketiga yang relative kecil yaitu sebesar 10 gal - 40 gal meliputi daearah Yogyakarta bagian barat dan timur dengan nilai intensitas sebesar III-IV MMI.

2. Secara umum, hasil pemetaan dari metode yang digunakan dalam penelitian ini menunjukkan bahwa daerah yang memiliki tingkat rawan kerusakan paling tinggi adalah daerah kabupaten Bantul serta sedikit wilayah Kulon Progo dan Gunung Kidul.

\section{DAFTAR PUSTAKA}

[1] Amir, Elnashai. 2006. The Yogyakarta Earthquake of May 27, 2006. Amerika : MidAmerica Earthquake Center

[2] Dobrin, M. B . Carl H Savit, 1988. Introduction to Geophysical Prospecting $4^{\text {th }}$ Edition, McGraw Hill Singapore (32-38).

[3] Dowrick, David J, 1987. Earthquake Resistant Design : For Engineers and Architects.

[4] Natawidjaja, D. H. 2005. Menyimak Gempa Bumi dan Tsunami Aceh 26 Desember 2004 Untuk Rekontruksi Aceh dan Mitigasi Bencana di Sumatera dan Daerah Lainnya. Makalah Potensi Gempa dan Tsunami. IAGI. Bandung.

[5] Reid H. F ., 1982. Elastic Rebound Theory of Earthquake. BSSA. Vol 11.

[6] Sulaiman, Ismail. 1980. Pendahuluan Seismologi. Akademi Meteorologi dan Geofisika, Jakarta. 